\title{
A influência da orientação à geração de valor ao acionista nas práticas de gestão de pessoas no ambiente da produção
}

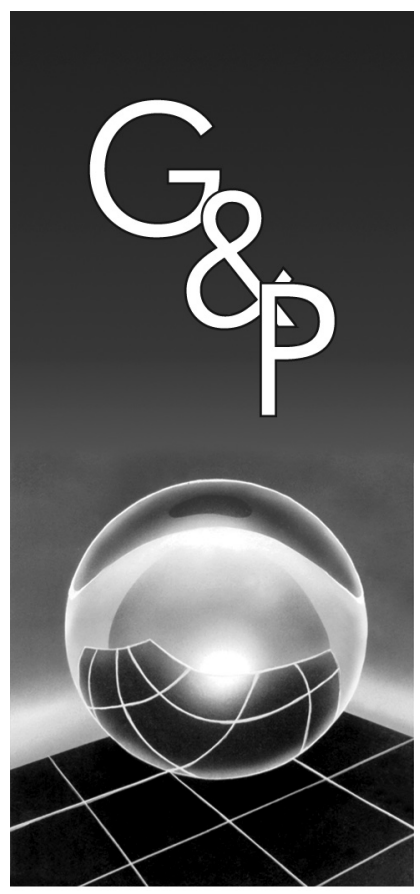

\author{
Roberto Marx \\ João Paulo Reis Faleiros Soares
}

Resumo

Este trabalho procura ampliar os conhecimentos a respeito da influência do enfoque na geração do valor aos acionistas sobre as práticas de gestão de pessoas, com ênfase no ambiente da produção. Inicialmente, o trabalho resgata as origens e os fundamentos da concepção financeira e da concepção da geração de valor ao acionista das empresas, em que o principal foco é a valorização do preço das ações. Em seguida, é analisada a interface que estas concepções possuem com as práticas de gestão de pessoas, explorando o caráter bidirecional desta interface, uma vez que a função recursos humanos não só é influenciada pelas diretrizes das empresas, mas também é tida como uma das principais formas para ajudar a difundi-las, tendo em vista seu papel de agente de mudança de comportamento nas empresas. Neste sentido, são aprofundados três principais elementos que compõem, segundo a literatura, esta interface: a remuneração variável, a gestão de desempenho e a autonomia no trabalho. Por fim, é apresentado um estudo de casos múltiplos que busca verificar como a concepção financeira das empresas vem influenciando, de fato, estas práticas relacionadas à gestão de pessoas no nível da produção de organizações que atuam no Brasil, assim como o quanto estas práticas têm contribuído para a difusão da mentalidade de geração de valor ao acionista. $O$ resultado deste estudo indica que, no plano conceitual, a influência da orientação à geração de valor ao acionista sobre as práticas de gestão de pessoas é nítida, mas que, na prática, ainda é pouco efetivada, apesar de mudanças já estarem ocorrendo nesta direção.

Palavras-chave: Geração de valor ao acionista. Gestão baseada em valor. Administração de recursos humanos. Desempenho no trabalho. Autonomia no trabalho. Remuneração variável.

\section{Introdução}

O presente trabalho tem como objetivo entender a influência da lógica da geração de valor ao acionista sobre as práticas de gestão de pessoas, dando enfoque no entendimento deste fenômeno ao nível da produção das empresas.

A lógica da geração de valor ao acionista vem ganhando força nas últimas décadas por uma série de fatores, sendo o principal a concentração das ações nas mãos de investidores institucionais, os quais exercem enorme pressão sobre os gestores das organizações em busca de um maior retorno sobre o investimento realizado nos papéis destas empresas. Como consequência, instaura-se nas empresas abertas uma nova mentalidade, segundo a qual todas as práticas devem convergir para a valorização do preço de suas ações.
Este cenário influencia praticamente todas as práticas de gestão das organizações inseridas neste contexto, inclusive as práticas de gestão de pessoas. Segundo a literatura existente, o principal elo entre a lógica da geração de valor ao acionista e a gestão de pessoas é a remuneração variável (STEWART, 1990; EHRBAR, 1998; STERN; et al., 2001). O pressuposto fundamental que rege esta questão é que os funcionários de uma empresa irão se comprometer com a "causa" da geração de valor ao acionista desde que parte deste valor gerado seja com eles compartilhada.

No entanto, a aplicação da remuneração variável, por si só, não garantiria a difusão da lógica da criação de valor. Para tanto, depreende-se da literatura pertinente, que este tipo de remuneração deve ser definido a partir de uma 
avaliação de desempenho preferencialmente individual e baseada em indicadores objetivos (financeiros, sempre que possível), que identifiquem os diferentes níveis de contribuição dos funcionários para a maximização de valor. Além disso, autores como Dutra (2004) e Hipólito (2002) afirmam que, para que a remuneração variável atrelada à avaliação de desempenho surta o efeito desejado, ela deve ser aplicada num ambiente em que haja autonomia suficiente a ponto de permitir esta busca por maiores patamares de desempenho.

Neste contexto, uma análise especialmente interessante a ser realizada é a respeito da prática de remuneração variável, das formas de avaliação de desempenho e da autonomia existente na produção das empresas. Apesar da aplicação da remuneração variável nos níveis executivos e em áreas comerciais já ser bastante difundida, nas áreas de operações, tem-se a percepção de que a adoção desta prática - principalmente com o objetivo explícito de maximizar o valor ao acionista - é menos intensa. Apesar disso, autores que advogam pela mentalidade da criação de valor ao acionista deixam clara a necessidade de se criar os corretos incentivos financeiros para o chão de fábrica (STERN et al., 2001).

Uma chave para este impasse é o desdobramento do conceito da autonomia no trabalho na produção. Quando é conferida a possibilidade de tomada de decisão ao funcionário (ou ao grupo de funcionários) acerca de temas da produção, uma alternativa é criada em termos de diferenciação de resultado e, consequentemente, de avaliação de desempenho e remuneração. Apesar de terem surgido por outros motivos, as novas formas de organização do trabalho respondem bem a necessidades da concepção financeira das empresas (ZILBOVICIUS; DIAS, 2005).

Desta forma, o presente trabalho busca trazer a discussão conceitual existente acerca destas questões e, posteriormente, entender o que está ocorrendo na prática com as empresas inseridas neste contexto, de forma a possibilitar uma releitura crítica dos conceitos abordados pela literatura previamente estudada. Para tanto, realizou-se um estudo de casos múltiplos com empresas que apresentam evidências de estarem inseridas em todo o contexto acima descrito. A hipótese explorada neste trabalho é a de que empresas inseridas no contexto da geração de valor para o acionista e que utilizam desenhos autônomos na produção estão caminhando para a adoção de práticas de remuneração variável atreladas ao alcance de resultados financeiros, apurados de forma individualizada. Estas práticas são aplicadas a todos os funcionários da produção, sendo a eles delegada a autonomia necessária para que sejam tomadas decisões que levem à criação de valor, de forma a fazer com que esta lógica seja difundida no ambiente da produção.

\section{A concepção de empresa voltada à geração de valor ao acionista}

Di Maggio (2001) organiza uma obra em que se busca entender o modelo de empresa do século XXI. Ao caracterizar este modelo, uma questão central é levantada: a imposição do controle do acionista sobre as empresas. Segundo este autor, até a década de 80 , os gestores de empresas estavam "protegidos" por monopolizarem informações e principalmente porque o controle acionário estava difuso. No entanto, no início da década de 80 , começa a se consolidar a chamada "concepção financeira da empresa", segundo a qual a empresa é vista como um portfólio de ativos, sendo a maior responsabilidade de seus executivos gerir a performance deste portfólio, analisando o desempenho de cada divisão da empresa, vendendo qualquer estrutura cujo desempenho financeiro fosse abaixo de investimentos alternativos. Neste contexto, a relação entre gestores e acionistas passa a ser vista como a de um agente para um "principal", conforme descrito na teoria da agência (FAMA, 1980).

Esta concepção de empresa ganha força em um contexto de mudança nos mercados de capitais. Useem (1996) trabalha o fato de as ações passarem a se concentrar, a partir do final da década de 70, nas mãos de grandes investidores institucionais, representados pelos gestores de fundos de pensão, fundos de investimentos e de companhias de seguros. A propriedade destas ações estaria nas mãos de milhões de acionistas, porém o poder de voto estava na mão de um pequeno número de instituições. A partir de então, estes investidores passam a exigir o foco da gestão nos lucros e, posteriormente, na valorização do preço das ações das quais são proprietários. Para garantir que os gestores atuassem de maneira a atender seus interesses, os investidores desenham pacotes de remuneração dos executivos atrelados ao resultado de curto prazo das empresas. Com o passar do tempo, os investidores começam a participar mais ativamente dos conselhos de administração das empresas e a influenciar suas gestões.

Feng et al. (2001) aprofundam este tema, discutindo sobre como o mercado de capitais faz a mediação entre o capital poupado pela classe média norte-americana e as empresas, entendendo o que ele fornece e o que exige em termos de retorno. Segundo os autores, a pressão por maiores rendimentos sobre as empresas é reflexo de uma sociedade cada vez mais "financeirizada". Neste país, aproximadamente $40 \%$ das famílias aplicam $10 \%$ de suas rendas anuais no mercado de capitais, formando uma provisão para suas aposentadorias. Esta pressão não se dá somente nas grandes corporações. O venture capital geralmente busca empresas em estágio embrionário, justamente porque deseja maiores retornos, apesar dos riscos também serem maiores. O private equity, por sua 
vez, é o capital que geralmente é alocado em empresas que já passaram pelo estágio inicial, à procura de oportunidades de revenda ou de abertura de capital destas empresas, momento em que se realiza o lucro. Assim sendo, o aporte destes tipos de capital sobre empresas de diversos tipos e tamanhos seria outra fonte de pressão sobre os gestores. Os autores concluem que empresas que têm estes players como principais acionistas ou controladores, dada a pressão exercida por eles, passam a ter a lógica financeira como principal norteador.

No decorrer da década de 80 , porém, começa a ganhar força uma nova concepção financeira das empresas, alternativa a ela: a concepção do valor para o acionista. Ela é uma extensão da concepção financeira, uma vez que a partir do momento que as empresas já focam no resultado financeiro, os acionistas começam a perceber que o retorno dado pelas empresas não estava sendo suficiente. "A idéia central na concepção de empresa voltada à geração de valor para o acionista é a de que o único propósito legítimo da empresa é maximizar o valor para o acionista" (FLIGSTEIN, 2002, p.148). Assim sendo, o principal indicador a ser utilizado é o preço da ação da empresa. Gestores foram instruídos a desinvestir em linhas de produtos não lucrativas, a enxugar suas estruturas, a fazer investimentos no core business (negócio central da empresa) e a reorganizar a estrutura de capital das empresas. Na concepção financeira ainda havia espaço para a diversificação, desde que o gestor buscasse gerir o conjunto de ativos de forma a maximizar o lucro como um todo. Já o movimento da geração de valor ao acionista privilegia grandes fusões, justamente para que haja maior foco, buscando-se fazer menos coisas, porém com maior eficácia. Neste sentido, uma relação com o desenvolvimento de core competences (competências essenciais ou centrais), conforme proposto por Hamel e Prahalad (1990), pode ser estabelecida.

Ainda na busca de explicitar as diferenças de concepções de empresas e suas consequências, Froud et al. (2000) caracterizam as lógicas produtivista e financeira das empresas, tangibilizando o que elas representam e como se diferenciam. Apesar de deixar claro que tais lógicas não são totalmente consistentes, e que não dominaram amplamente o mercado por todo um período, ambas exerceram forte influência nos momentos em que estiveram em voga. O estereótipo da lógica produtivista (predominante na década de 80) é caracterizado pela competição por processos e produtos, foco em menores tempos de produção, menores estoques, maior qualidade, e pela liderança para empresas japonesas. Já o estereótipo da lógica financeira (predominante na década de 90) seria formado pela competição universal por resultados financeiros, sendo o retorno sobre o investimento de uma empresa explicitamente comparado com o de todas as outras, independentemente do segmento de atuação, pela pressão por meio do mercado de capitais, pelo desafio para a gestão, representado em termos estritamente financeiros, e pela liderança das empresas norte-americanas. Os autores ressaltam que a "financeirização", de fato, conota mudanças reais importantes, mas que apresenta incoerências e que, principalmente, não é um fenômeno realizável para a gestão (pois envolve questões estruturais que fogem de sua competência).

Seguindo esta linha, tanto Di Maggio (2000) quanto Froud et al. (2000) apontam diversas fragilidades da lógica financeira e da geração de valor ao acionista, tais como: excessivo foco em resultado de curto prazo e o menor investimento em pesquisa e desenvolvimento. A adoção de modelos de gestão baseada em valor ao acionista (que serão abordados a seguir) estaria muito associada a produtos e serviços de consultorias, e potencializa a pressão exercida por investidores. Apesar destas fragilidades apontadas, todos os autores citados deixam claro que a lógica de criação de valor para o acionista tem sua força própria e que, portanto, não pode ser desprezada.

\subsection{Modelos de gestão baseada em valor}

É no contexto acima explicitado que surgem os diversos modelos de gestão baseada em valor. Subentende-se que o termo "valor" ao qual eles se referem diz respeito aos acionistas, e não a quaisquer outras partes interessadas. Segundo Froud et al. (2000), várias consultorias de renome global elaboraram modelos e métricas próprias para medir a contribuição da empresa para a criação de valor aos acionistas, modelos estes que ajudam a viabilizar os conceitos acima expostos, elucidando como a lógica de criação de valor ao acionista deve permear as decisões e as práticas empresariais. O modelo de maior repercussão é o economic value added, ou valor econômico agregado, daqui em diante chamado apenas de EVA, que inicialmente representou um indicador criado pela Stern \& Stewart Co, mas que depois se tornou símbolo de um modelo de gestão abrangente.

Stewart (1990) argumenta que o papel mais importante da gestão sênior das empresas deve ser a de maximizar o valor de mercado corrente da empresa. O autor, um dos principais teóricos do EVA, trabalha a necessidade de se ter uma métrica precisa para que as empresas a utilizem como principal parâmetro. Segundo ele, medidas contábeis tais como lucro, lucro por ação e retorno sobre o patrimônio líquido são totalmente inadequadas, pois não se relacionam diretamente com o preço das ações. O foco das empresas deveria ser maximizar o EVA, que seria "a única medida diretamente ligada ao valor de mercado intrínseco". Genericamente, o indicador é definido como "lucro operacional menos o custo de todo o capital empregado para produzir este lucro" e, algebricamente, é representado da seguinte forma (Equação 1) (EHRBAR, 1998): 


$$
\mathrm{EVA}=\mathrm{NOPAT}-\mathrm{C} \%(\mathrm{TC})
$$

sendo NOPAT: lucro operacional líquido após taxas; C\%: porcentagem de custo de capital; e TC: capital total.

Um dos pontos mais relevantes desta medida é a cobrança pela utilização do capital, que antes de seu aparecimento pouco era explorada. Desta forma, a gestão com base na maximização do EVA eleva a exigência sobre as empresas, não bastando a elas que o lucro seja positivo. Se o EVA é positivo, diz-se que a empresa gerou valor para o acionista. Caso contrário, o valor foi destruído.

Além do cálculo do EVA em si, os autores argumentam que é necessário que as empresas estabeleçam também os direcionadores de valor. Estes direcionadores são elementos, mensurados em termos financeiros ou não, que irão influenciar diretamente o EVA. Na prática, estes direcionadores assumem enorme importância, pois tangibilizam o EVA para os diversos níveis da organização, funcionando como elementos de desdobramento deste indicador. Na maior parte das vezes é sobre estes direcionadores que os gestores em geral poderão agir, apesar de nunca se poder perder o foco na variação do EVA.

Para que os modelos de gestão baseada em valor funcionem nas empresas, aponta-se como fator central o alinhamento dos incentivos oferecidos aos executivos. Segundo todos eles, é condição necessária para a implementação eficaz destes modelos que os incentivos sejam redistribuídos, de forma a fazer com os funcionários se sintam e ajam como donos do negócio. Para tais autores, é fundamental que seja concedido bônus que compartilhe com os executivos o valor criado. Para tanto, o EVA deve ser medido nas diversas unidades e linhas de operação, sendo ele a única medida interna de medição de desempenho. Além disso, ainda são recomendados, em termos de remuneração variável, planos de stock options.

Stern et al. (2001) sugerem que o conceito de remuneração variável seja empregado em todos os níveis da organização, inclusive na produção. Segundo eles, a meta deveria estar, como em qualquer outra área da empresa, relacionada ao EVA da unidade (neste caso, ao EVA da planta). Para que esta métrica não fique muito distante dos operadores, indicadores operacionais que influenciam diretamente o EVA da fábrica (ou seja, os direcionadores de valor) devem ser as métricas cobradas e acompanhadas, uma vez que é sobre eles que os funcionários têm capacidade de atuar. Estes autores não negligenciam a questão da negociação com os sindicatos, que deve ser realizada explorando-se os ganhos em termos de remuneração e também de transparência que esta forma de atuação pode trazer aos funcionários da produção, uma vez que eles receberiam treinamentos sobre conceitos financeiros e seriam comunicados mensalmente acerca do desempenho de suas unidades.
A delegação de autonomia para a tomada de decisão também é vista como pressuposto para o funcionamento do sistema de incentivos no nível da produção. Stern et al. (2001) enfatizam a existência de um grande "reservatório" de conhecimento sobre o processo produtivo que pode emergir e ser utilizado de forma a contribuir efetivamente para o resultado da companhia se os trabalhadores participarem dos incentivos baseados no EVA.

\section{As práticas de gestão de pessoas}

À medida que se aprofunda o entendimento da concepção financeira e da geração de valor ao acionista, fica claro que as mais diversas práticas de gestão adotadas nas empresas acabam sendo influenciadas por esta nova lógica. Neste contexto, é de se esperar que a gestão de pessoas também passe por esta transformação. Apesar de ser influenciada por esta lógica da mesma forma que as demais funções da empresa, a função Recursos Humanos apresenta um papel especial. É esperado que ela ajude a promover as mudanças nas demais áreas e funções da empresa.

\subsection{Práticas de remuneração variável atreladas à gestão de desempenho e à autonomia}

Conforme ficou claro a partir dos autores que tratam da gestão baseada em valor (STEWART, 1990; EHRBAR, 1998; STERN et al., 2001), o principal ponto de ligação apontado pela literatura entre a lógica da criação de valor para o acionista e a gestão de pessoas é a remuneração variável. No entanto, para que sejam implementadas as práticas de remuneração variável, é necessário haver um sistema de gestão de desempenho, por meio do qual sejam estipuladas metas, mensurados os resultados alcançados e estimulada continuamente a melhoria do desempenho (conforme visto anteriormente, autores que advogam por modelos como o EVA afirmam que estas medidas devem ser poucas, senão apenas uma).

Antes de se aprofundar a discussão da literatura existente sobre os temas acima citados, vale citar que muito pouco é encontrado acerca de práticas de gestão de pessoas relacionadas à lógica de geração de valor. Dificilmente se encontram textos - principalmente entre autores brasileiros - que tratem diretamente de "como as práticas de RH podem ajudar a empresa a tornar-se mais rentável". Há, aparentemente, uma reticência por parte da maioria dos estudiosos de $\mathrm{RH}$ em discutir este contexto, preferindo estes autores estudar abordagens alternativas, baseadas no respeito ao equilíbrio entre os interesses dos diversos stakeholders de uma empresa, na responsabilidade social empresarial ou na qualidade de vida no trabalho. Outra possível explicação para a carência de reflexão da relação entre políticas e práticas de $\mathrm{RH}$ e a lógica financeira estaria no fato de que para os autores 
ligados à RH, esta influência parecer natural sendo, portanto, um tema de menor relevância. De outro lado, na área de ciências sociais e, especificamente, na sociologia do trabalho, a questão das políticas internas de RH e a lógica empresarial como um todo tem atraído pouca atenção, talvez pelo fato da lógica capitalista ser aquela que hoje prevalece sem concorrência de modelos alternativos o que contribuiria para esta lacuna na produção intelectual.

\subsubsection{A remuneração variável}

Segundo Hipólito (2002), os diversos sistemas de recompensa existentes buscam simbolizar o quanto o indivíduo vale para a organização. Assim, as organizações buscam alinhar a compensação de seus funcionários à sua contribuição, evitando gerar desequilíbrios entre a estrutura compensatória e os resultados práticos obtidos. Historicamente, a principal referência para os sistemas de compensação era o cargo. No entanto, esta referência dificulta o reconhecimento de pessoas de maneira diferenciada conforme a contribuição para os objetivos organizacionais. Assim, surgem outros sistemas de remuneração que buscam discriminar a "entrega" feita pelos diferentes profissionais, seja em função da responsabilidade esperada de sua atuação, seja por resultados efetivamente alcançados por eles.

A partir destes conceitos, o autor trabalha com três grandes componentes da compensação: remuneração variável (que pode ser de "longo prazo" e de "curto prazo"), a remuneração fixa (salário e benefícios), e o que denominou de "formas de recompensas alternativas" (tais como promoções, acessos a programas de desenvolvimento etc.).

A remuneração variável, em suas diversas formas, está atrelada aos resultados alcançados. Além de enfatizar a cultura de resultado, ela reduz custos fixos e vale-se de incentivos fiscais. Trata-se de retribuição pelo alcance de um ou vários objetivos organizacionais (no contexto que está sendo estudado, a valorização do preço da ação das empresas). Seu objetivo é fazer do funcionário um parceiro nos negócios da empresa. Segundo Chiavenato (1999) e Marras (2002), faz sentido utilizá-la quando existe uma clara relação entre o esforço do funcionário e a quantidade de resultados. Em casos em que isso não é de possível identificação ou quando os funcionários não controlam os resultados (como em linhas de montagem), talvez não seja apropriada.

A literatura aponta que a remuneração variável pode se manifestar de diversas maneiras nas empresas, sendo que nem todas elas necessariamente são eficazes na obtenção do comprometimento do funcionário com os resultados organizacionais. Wood Jr. e Picarelli Filho (1999) conceituam dois grandes grupos ou tipos de remuneração variável: a participação nos lucros e a remuneração por resultados. A primeira tem como base os resultados globais da empresa, enquanto a segunda parte de metas e objetivos negociados entre empresa e funcionários. A participação nos lucros teria um fator motivador menos intenso, já que o vínculo entre a ação individual e a recompensa nem sempre é claro. Geralmente este tipo de remuneração variável distribui valores de forma eqüitativa a todos os funcionários, o que ressalta sua desvantagem em termos motivacionais, já que não recompensa os diferentes níveis de esforços. Já a remuneração por resultados recompensa o desempenho medido nas esferas individual, da equipe ou mesmo da organização.

A literatura apresenta diversos modelos de remuneração por resultados. A remuneração por performance recompensa os funcionários pelo alcance de metas préestabelecidas, geralmente alinhadas com os objetivos da empresa. A distribuição de ações como forma de compensação pelos resultados conseguidos implica a distribuição dos papéis da companhia ao invés de valores monetários. Ela busca tornar o comprometimento do funcionário com a empresa ainda maior, por torná-lo um de seus sócios. Geralmente se restringe aos níveis estratégicos da organização. A distribuição de opções de compra de ações da companhia (stock options) dá ao funcionário o direito de comprar um lote de ações da empresa por um determinado preço, sendo que o direito de compra deve ser exercido dentro de um prazo previamente determinado.

\subsubsection{Os sistemas de gestão de desempenho}

A avaliação de desempenho funciona na maioria das vezes como um pré-requisito da remuneração variável, já que permite aferir o desempenho do funcionário ou do grupo, de forma a, seguindo critérios pré-estabelecidos, determinar os valores a serem pagos. No entanto, trata-se de uma prática amplamente utilizada no mercado, utilizando métodos completamente distintos e objetivos diversos.

Marras (2002) conceitua a avaliação de desempenho como sendo um instrumento gerencial que permite mensurar os resultados obtidos por um empregado ou por um grupo, em determinado período. Ela pode possuir diversas dimensões, tais como a de potencial, a de análise comportamental, a de aferição de conhecimento, a de desenvolvimento profissional e finalmente as de realização de metas e resultados (HIPÓLITO; REIS, 2002; MARRAS, 2002). Nesta dimensão, busca-se aferir quantitativamente a lacuna existente entre os resultados esperados, sejam eles grupais ou individuais, e os efetivamente alcançados.

É de se ressaltar a busca constante pela utilização de indicadores quantitativos na avaliação de metas e resultados. Isso leva a uma maior objetividade e concretude ao processo. Para Wood Jr. e Picarelli Filho (1999), os sistemas de medição de desempenho organizacional 
e os de medição de desempenho grupal ou individual, utilizados para remuneração, devem ter um grande alinhamento, se não forem, inclusive, o mesmo. Como é possível verificar por meio da Figura 1, idealmente deve haver uma hierarquia de indicadores, em que medidas mais específicas, sob responsabilidade de uma pessoa ou um grupo, estão contidas em medidas mais amplas e complexas, que avaliam o desempenho da organização como um todo.

Neste sentido, percebe-se o alinhamento com que Stern, Shiely e Ross (2001) ressaltam quando tratam da utilização do EVA como indicador principal e dos direcionadores de valor como indicadores a serem utilizados na produção.

\subsubsection{A autonomia no trabalho}

Segundo Useem (1996), investidores institucionais são assertivos ao afirmar que "não querem dizer (aos gestores) como devem gerir suas empresas; eles só querem uma empresa bem gerida". Ou seja, toda a lógica de geração de valor ao acionista está calcada numa grande pressão por resultados, mas acompanhada de grande autonomia para que se alcance altos retornos exigidos. Esta autonomia é conferida aos presidentes executivos pelos conselhos de administração, mas é um pressuposto do modelo de gestão baseada em valor que ela seja disseminada pela companhia.

Para que haja maior compreensão acerca da autonomia no trabalho em todos os níveis da organização, é necessário estudar a questão da organização do trabalho. Segundo Salerno (1998), a autonomia relativa a um grupo de trabalho depende fundamentalmente do esquema organizacional no qual este grupo exerce suas funções. No início do século XX, com o advento da administração científica, a autonomia na produção era praticamente nula. A divisão entre a concepção do método de trabalho e sua execução, que resultava em tarefas prescritas e de escopo delimitado, assim como o controle constante, caracterizavam uma

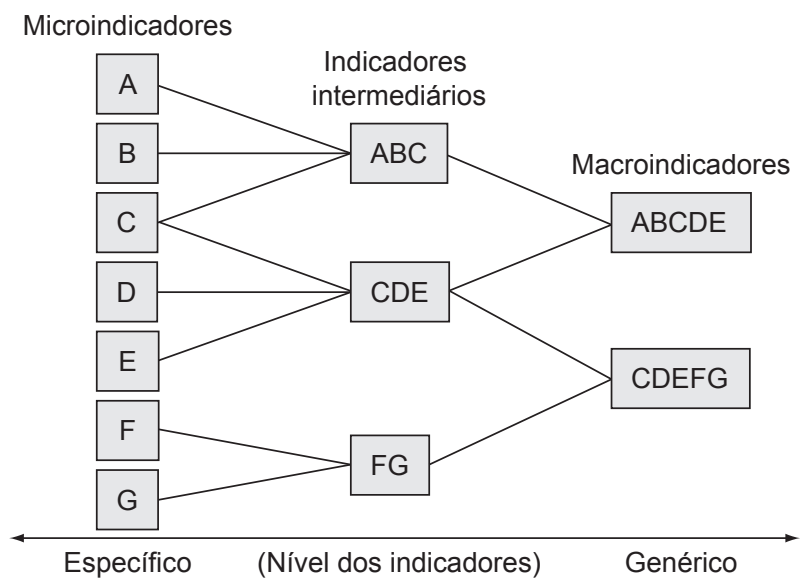

Figura 1. Princípio da hierarquia de indicadores. Adaptado: (WOOD Jr.; PICARELLI FILHO, 1999). forma de se trabalhar em que pouca ou nenhuma capacidade decisória era exigida do trabalhador.

No entanto, a evolução dos cenários competitivos fez com que esta abordagem se mostrasse limitada. Muitas empresas passaram a competir de novas formas, necessitando de maior flexibilidade na maneira de atuação e comprometimento crescente de seus funcionários. Os sistemas de punição e controle e de prescrição do trabalho deixam de responder de forma satisfatória a este novo ambiente.

Neste contexto, novos modelos organizacionais foram testados. Uma das mudanças se baseou justamente na crescente autonomia decisória de equipes e indivíduos, que chegava até o chão de fábrica. A idéia era que, com maior autonomia, os funcionários ligados à produção reagiriam de forma mais rápida e eficaz tanto a mudanças externas ao processo produtivo (como a chegada de novos pedidos ou até mesmo produtos), quanto a problemas da produção (como uma falha inesperada de máquinas, falta de insumos, etc.).

Uma das maneiras de se elevar a autonomia do trabalho na produção é por meio da adoção dos chamados grupos semi-autônomos. Segundo Marx (1997), esta forma de se organizar o trabalho pode responder com eficácia aos requisitos de flexibilidade e demais exigências do mercado. Concebido pelos autores da escola sociotécnica de organização do trabalho, em reação ao modelo clássico, o grupo semi-autônomo deveria assumir responsabilidade completa pela produção de uma linha de produtos, que passa da exclusiva operação de máquinas para questões relacionadas ao controle da produção, à gestão da qualidade, à manutenção dos equipamentos, etc. Decisões a respeito das atividades desempenhadas e de suas prioridades devem ser tomadas pelo grupo. Assim sendo, os componentes do grupo, via de regra, têm condições de interferir nos resultados dos indicadores de desempenho definidos e sobre os quais serão traçadas suas metas.

Salerno (1998) explora o relacionamento entre a atuação dos grupos semi-autônomos e as metas de produção. Segundo o autor, as metas referentes aos indicadores de desempenho estabelecidos não deveriam ser simplesmente impostas. Para que haja efetividade na ação, seria necessário constituir um processo de comunicação (de base normativa) que visasse à validação das metas pelo grupo e a redefinição das metas. Quando cita a dimensão normativa da comunicação, o autor se refere ao alinhamento dos envolvidos quanto à compreensão sobre o que é mais relevante do ponto de vista da lógica da eficiência e dos objetivos da produção. Em tese, seria necessário abrir espaço para discussão sobre a viabilidade de se atingir as metas em função das condições e da quantidade de recursos, da capacitação e da própria autonomia. Este espaço pode ser viabilizado, por exemplo, por meio de reuniões regulares destinadas a este tipo de 
comunicação, às quais todos os membros dos grupos semi-autônomos deveriam ter acesso.

Zilbovicius e Dias (2005) exploram como as novas formas de trabalho, calcadas na autonomia, aderem à lógica financeira. A descentralização da decisão até os menores níveis da organização é relevante para se maximizar os direcionadores de valor, e não simplesmente o volume de produção (é enfatizado, inclusive, que os direcionadores de valor assumem também um caráter doutrinário no chão de fábrica). Os operadores têm que saber lidar com a aleatoriedade, com o que não pode mais ser prescrito, já que a estabilidade pressuposta pela escola clássica muitas vezes não existe mais. $\mathrm{O}$ empowerment se faz ainda mais importante num cenário de enxugamento pelo qual é natural que as empresas voltadas à criação de valor passem, em que a baixa gerência ou o nível de supervisão são reduzidos ou até extintos. O principal ponto ressaltado pelos autores é que a "financeirização" e as novas formas de organização possuem muitos pontos em comum (tais como, o foco nos resultados, ao invés do foco nas tarefas ou procedimentos, maior responsabilidade aos funcionários, crença na instabilidade, etc), de tal forma que se torna possível afirmar que as novas formas de organização podem facilitar a difusão da lógica financeira. No entanto, eles deixam claro que as novas formas de organização não nasceram como resposta à financeirização e que existem divergências entre os princípios da escola sociotécnica, que propôs novos arranjos organizacionais baseados na autonomia e a lógica financeira.

Finalmente, para que a autonomia dê resultados em termos de criação de valor, novamente é ressaltado que ela precisa ser suportada por outros mecanismos, tais como esquemas de remuneração, de avaliação e de comunicação. A combinação destes elementos, segundo a literatura acima apresentada, tende a gerar maior comprometimento com os objetivos organizacionais. É natural que a autonomia seja acompanhada pelo aumento da responsabilidade sobre os funcionários e que, neste cenário, aumente a pressão por parte deles pela remuneração variável, uma vez que eles passam a se considerar protagonistas na geração dos resultados alcançados. Desta forma, é necessário que sejam definidos e divulgados os indicadores de desempenho pelos quais indivíduos ou grupos serão avaliados, assim como a maneira pela qual serão recompensados caso as metas sejam atingidas, de forma que todos tenham clareza de como funciona este processo. Neste sentido, há nova convergência com os autores da gestão baseada em valor: Stern, Shiely e Ross (2001) consideram a transparência e a comunicação como sendo um ponto bastante positivo para os funcionários, propondo, inclusive, que este argumento seja utilizado com os sindicatos, em casos de resistência à implementação das novas práticas de remuneração (variável, no caso).

\subsubsection{Gestão de pessoas, inovação e organização do trabalho: relato de casos presentes na literatura internacional}

A pesquisa realizada pelos autores pode se beneficiar de relatos e análises presentes na literatura e que podem ser considerados bem sucedidos ao introduzir grupos semi-autônomos e práticas "agressivas" de gestão de pessoas, incluindo-se nestas práticas, a distribuição de ações e de outras formas de vincular todos os funcionários da empresa ao processo de geração de valor ao acionista.

Hamel (2007), por exemplo, relata os casos das empresas Google, Whole Foods Market e Gore Inc, as quais, atuando em setores muito diferentes entre si, têm em comum as características acima e o fato de serem exemplos de empresas extremamente bem sucedidas em termos empresariais e aos olhos de seus acionistas.

Hargadon e Fanelli (2002) e Hansen et al., (1999) também estudam empresas americanas e chegam à conclusão que o fato de serem todas empresas continuamente desafiadas pela inovação radical, esse fato as estimula e as incentiva a se organizarem de forma a priorizar o trabalho em equipe, com poucos níveis hierárquicos e lastreadas em iniciativas de gestão de pessoas fortemente baseadas em remuneração variável, em estímulo à geração de valor aos acionistas e aos resultados empresariais.

Se de um lado os autores estudaram empresas que têm como prioridade a inovação contínua e radical, cabe perguntar se as iniciativas de gestão que estas empresas colocaram em prática também poderiam ser encontradas em outros ambientes onde a inovação não é um diferencial competitivo tão poderoso. Respostas a estas perguntas deverão ser dadas com base em estudos de casos de empresas operando no Brasil, cujo relato é feito no próximo item.

\section{Metodologia e apresentação dos casos}

Para se realizar a pesquisa de campo pretendida, é necessário restringir o campo de observação e observar empresas que realmente estejam inseridas no contexto estudado. Portanto, foram adotadas as seguintes características como critérios para selecionar as empresas a serem observadas:

a) Estar inserida em contexto da lógica da geração de valor ao acionista. Como critérios para verificar esta condição, foram adotados os seguintes:

- ser empresa listada em bolsa de valores, seja no Brasil, seja no país de origem (em caso de empresas multinacionais);

- ter participação acionária de investidores institucionais ou instituições financeiras; e 
- adotar, preferencialmente, algum modelo de gestão de valor para o acionista (este critério não será eliminatório).

b) Ser reconhecida por adotar modelos de organização do trabalho flexíveis, conferindo autonomia a seus profissionais da produção.

A aplicação destes critérios no universo de empresas que atuam no país faz com que o tamanho da amostra passível de ser observada seja reduzido. Além disso, o fenômeno pesquisado é relativamente recente, sendo que pouco foi encontrado na literatura a respeito de sua relação com as práticas de gestão de pessoas, mais especificamente de remuneração variável, no ambiente da produção das empresas. Por estas razões, uma metodologia de pesquisa apropriada é o estudo de caso.

Segundo Eisenhardt (1989), o estudo de fenômenos recentes em ciências sociais, que focam o entendimento de dinâmicas presentes em realidades particulares, se enquadram na estratégia de pesquisa denominada estudo de caso.

No que tange à seleção da amostra, a autora ressalta que, em estudos de caso, ela deve ser teórica, e não randômica. Os critérios utilizados são os acima expostos, além da acessibilidade às empresas. Foram selecionadas quatro empresas, considerando a recomendação da autora, segundo a qual um estudo de casos múltiplos deve contemplar no mínimo quatro e no máximo dez empresas.

No presente trabalho, foram realizadas entrevistas semi-estruturadas com gerentes da produção e gerentes de recursos humanos das empresas pesquisadas. Foi ouvido também um representante sindical, uma vez que o fenômeno estudado envolve mudanças que podem gerar conflitos de interesses entre empresas e sindicatos. Nestas entrevistas buscou-se identificar se as mudanças estão ocorrendo como respostas à pressão pela criação de valor e, ao mesmo tempo, como forma de ajudar a propagar esta mentalidade. Dentre as questões exploradas nas entrevistas, destacam-se as seguintes:

a) quais são os principais objetivos da empresa?

b) quais são os principais indicadores e metas relacionados a estes objetivos?

c) como se organiza o trabalho na produção? Como funcionam os grupos?

d) qual o nível de autonomia no chão de fábrica?

e) como as pessoas, nos diversos níveis (principalmente no ambiente da produção) são avaliadas?

f) há definição de metas para os grupos?

g) como se busca o entendimento dos funcionários acerca da definição e apuração de metas?

h) como as pessoas, nos diversos níveis (principalmente no ambiente da produção) são recompensadas em termos de remuneração variável? i) qual é o entendimento dos funcionários da produção acerca do modelo de remuneração variável aplicado a eles?

j) a remuneração variável tem ajudado a promover o alinhamento entre os objetivos da empresa e do funcionário?

Além das entrevistas semi-estruturadas, buscou-se confirmar a consistência dos dados fornecidos pelos entrevistados por meio da observação de materiais de comunicação interna e externa (cartazes, folders, textos disponíveis em Intranet e Internet, etc.) e de outras evidências relacionadas ao tema pesquisado, de forma a permitir a triangulação de dados.

Por meio destas técnicas de pesquisa, buscou-se explorar as seguintes variáveis:

a) a presença da lógica de geração de valor ao acionista nas empresas;

b) os grupos semi-autônomos;

c) a utilização de ferramentas de avaliação de desempenho e de remuneração variável na produção; e

d) a difusão da lógica da geração de valor ao acionista na produção.

Os resultados da coleta dos dados são apresentados a seguir.

\subsection{As empresas}

Conforme citado, buscou-se obter um conjunto de organizações em que o contexto discutido no presente trabalho fizesse sentido. Assim sendo, todas as empresas estudadas possuem ações listadas em bolsa de valores de países em que os mercados de capitais são extremamente desenvolvidos (todas são multinacionais, com capital aberto em seus países de origem e, no único caso em que a empresa não é de origem norte-americana ou britânica, a empresa também tem suas ações negociadas em um destes dois mercados). As quatro empresas escolhidas possuem participação, direta ou indireta, de investidores institucionais. Mais de $75 \%$ das ações de duas das quatro empresas estão em suas mãos. Outra empresa possui como um de seus acionistas mais relevantes uma das maiores empresas seguradoras do mundo. A única empresa estudada que não tem alta concentração de suas ações nas mãos de investidores institucionais tem como acionista majoritária uma outra empresa que tem quase metade de suas ações em poder deste tipo de investidor.

Além disso, todas as empresas estudadas adotam desenhos flexíveis na produção em suas operações no Brasil, desenhos estes que de alguma forma se referenciam nos grupos semi-autônomos conceituados em Marx (1997) e Salerno (1998). Este fato é um bom indicador de que se confere algum grau de autonomia aos trabalhadores da produção.

A empresa 1, de origem britânica, possui quatro grandes unidades de negócios. A unidade fabril instalada 
no Brasil pertence à unidade de motores aeronáuticos, e conta com aproximadamente 260 funcionários e 100 prestadores de serviços. Esta planta localiza-se na cidade de São Bernardo do Campo (SP) e presta o serviço de manutenção de tais equipamentos caracterizando-se, portanto, produção de baixa escala sob encomenda.

A segunda empresa analisada (empresa 2) atua no setor de produtos de higiene pessoal, do lar e profissional. Trata-se de uma joint venture firmada em 1998 por uma grande multinacional de capital norte-americano e empresas brasileiras tradicionais no ramo. A empresa possui duas grandes unidades de negócios: uma de personal care, e outra que atende o ramo institucional. $\mathrm{O}$ foco desta pesquisa é sobre a unidade de personal care, localizada em Suzano (SP), em que há 600 funcionários diretos e 500 terceirizados. A produção nesta unidade é caracterizada por altos volumes, com uso intensivo de tecnologia.

A empresa 3 atua na área de produtos de beleza e é também originária dos EUA, onde possui capital aberto. Ela está presente no Brasil há mais de 40 anos e emprega cerca de 4.300 funcionários. A unidade fabril analisada situa-se na cidade de São Paulo e conta com aproximadamente 1.400 funcionários, sendo que 1.000 destes funcionários dedicam-se à operação.

Por fim, a última empresa estudada (empresa 4) é de origem multinacional e possui três divisões de negócios globais: beleza, higiene e alimentos. Em seu país de origem (Europa) possui capital aberto, assim como no mercado norte-americano. A empresa apresenta diversas unidades fabris no Brasil, sendo que a unidade analisada encontra-se em Indaiatuba (SP) e destina-se à fabricação de produtos de limpeza.

Apresentadas as empresas, parte-se, agora, à descrição de suas realidades no que tange aos pontos centrais do presente trabalho.

\subsection{A presença da lógica de geração de valor ao acionista nas empresas}

A partir das entrevistas realizadas e dos demais dados coletados em campo, pode-se afirmar que, ao menos nos níveis gerenciais, a lógica de geração de valor ao acionista está presente. A empresa 4, por exemplo, utiliza indicadores formais de geração de valor para seus acionistas (no caso, a empresa utiliza o TSR - total shareholder return - indicador que de forma análoga ao EVA se propõe a medir a criação de valor para os acionistas). A partir de um discurso do principal executivo da área financeira da empresa, de fevereiro de 2006, percebe-se claramente o foco em utilização eficiente de capital e no aumento de margens, em detrimento de market share. Segundo o executivo, o objetivo em longo prazo da empresa é gerar valor superior para os acionistas da empresa, estando, em
2010, no terço superior do ranking das empresas do setor em TSR.

Já na empresa 2, a busca pela geração de valor para o acionista e, pensando-se localmente, pelo retorno sobre o capital empregado na operação brasileira, é vista como prioritária. Por ter realizado um grande investimento em maquinário quando da chegada da empresa majoritária americana, a pressão pelo retorno sobre o capital investido na empresa é grande. O principal objetivo atual da empresa é o crescimento em vendas (única forma de rentabilizar a operação após tamanho investimento) e no lucro operacional. Outra evidência do foco na geração de valor é o fato de todos os funcionários das unidades administrativas terem, como tela inicial de sua intranet, a cotação da ação na bolsa de valores de Nova York. Este foco na geração de valor para o acionista é reforçado ainda pela adoção, para os executivos da empresa, de incentivos de longo prazo na forma de opções de ações.

$\mathrm{Na}$ empresa 1, é claro para todos os funcionários que um agressivo retorno sobre o capital empregado é esperado. A preocupação com o retorno financeiro está presente por meio de uma das quatro grandes metas do grupo em nível global, qual seja atingir, em 2010, um return on capital employed (ou retorno sobre capital empregado, devorante ROCE) de 30\%. Esta meta está exposta junto à porta da fábrica, de forma muito visível, junto aos outros três objetivos macro da empresa.

Por fim, na empresa 3, o foco no resultado financeiro também é bastante presente, apesar de estar menos explícito que nas outras empresas estudadas. Ressaltam-se, internamente, tópicos como crescimento de vendas, imagem da marca e aparência dos produtos. No entanto, a busca pela otimização da estrutura de custos é uma das seis prioridades estratégicas da empresa. Além disso, é disseminada a todos os funcionários a importância do resultado financeiro. A totalidade dos funcionários é cobrada por indicadores financeiros (inclusive os operadores), o que faz com que a preocupação com a rentabilidade acabe permeando de alguma forma, as decisões do cotidiano.

Vale ressaltar que, em todas as quatro empresas estudadas, gestores de produção e níveis acima são cobrados e remunerados principalmente por indicadores financeiros (em detrimento de indicadores operacionais).

\subsection{Os grupos semi-autônomos}

Conforme exposto no início desta seção, as empresas escolhidas utilizam algum tipo de sistema flexível de organização do trabalho na produção. Na empresa 1 , o conceito de times autogeridos foi introduzido no início de 2004. Nestes grupos, cujos membros são responsáveis não só pela produção, mas também por assuntos relacionados à qualidade, recursos humanos, orçamento, entre outros, há um monitor para cada um destes assuntos, além de um faci- 
litador do grupo, eleito pelo grupo a cada seis meses e que exerce papel de liderança. Os monitores fazem a interface com as demais áreas da empresa, como vendas, área financeira e RH. Ao grupo são sugeridas metas pela direção da empresa, pelas quais se tornam responsáveis, sendo que o status em relação a elas deve ser reportado mensalmente. Segundo o gerente de recursos humanos, a implementação deste tipo de organização ainda não está no nível desejado.

$\mathrm{Na}$ empresa 2, quando se decidiu realizar os investimentos em alta tecnologia já mencionados, percebeu-se que sua equipe não estava capacitada para utilizá-la. Assim, em 1998, um extenso programa de capacitação foi realizado. Suprida esta deficiência em capacitação, a empresa entende que a produção está suficientemente madura para iniciar a implementação dos grupos semi-autônomos, formando células com maiores responsabilidades, que não se limitam somente a operar as máquinas, mas também a desempenhar atividades de manutenção, gestão da qualidade, planejamento, entre outras.

Já a empresa 3 adota grupos semi-autônomos em 2003 visando ajudar a reverter o resultado da empresa em um momento de forte crescimento de concorrentes. Com a implementação dos grupos, o papel de inspetor de linha foi extinto, e os próprios funcionários passaram a exercer funções de setup e ajuste de máquinas, controle de qualidade e controle da produção em si. Cada grupo possui um conjunto de indicadores operacionais pelo qual são responsáveis. Vale destacar que na fábrica também são expostos os indicadores financeiros a partir dos quais são desdobrados os indicadores operacionais.

No entanto, o entendimento destes indicadores e, principalmente, de como eles se inter-relacionam, não é trivial para os operadores. Por isso, a empresa ofereceu uma capacitação básica de operação dos equipamentos, além de português e matemática. Outra parceria foi estabelecida em 2005 para ajudar os operadores a trabalharem com conceitos utilizados no dia-a-dia, dentre eles os indicadores de desempenho.

A empresa 4 também está organizada por meio de grupos semi-autônomos. No entanto, ainda existem supervisores. Porém, operadores são polivalentes, sendo capazes de atuar em diferentes pontos das linhas. Além disso, mesmo com supervisores, as linhas adotam líderes para assuntos funcionais, tais como aqueles que tratam do Programa de Participação nos Resultados (PPR) da empresa.

\subsection{A utilização de ferramentas de avaliação de desempenho e de remuneração variável na produção}

Inicialmente, é importante notar que as quatro empresas estudadas apresentam, no nível da produção, ferramentas formais de avaliação de desempenho quantitativas (com base em indicadores) e, atreladas a elas estão modelos de remuneração variável. Cada uma delas apresenta características diferentes e encontra-se em diferentes níveis de implementação.

Na empresa 1, a partir de 2003, com o intuito de divulgar de forma concreta para todos os funcionários da empresa os objetivos da organização e os individuais, passou-se a utilizar o que denominam "metodologia das pirâmides". A organização possui uma pirâmide (que é física, e está localizada na entrada da fábrica), sendo que em cada uma de suas quatro faces há um macroobjetivo (dentre eles, o financeiro, medido pelo ROCE). Estes objetivos são desdobrados ao nível departamental $\mathrm{e}$, posteriormente, individual. Cada funcionário possui uma pirâmide de cartolina, que contém em cada face seus objetivos individuais válidos para o ano. Estas metas, a partir de 2004, passaram a ser vinculadas ao PPR, estruturado pela empresa em parceria com uma representação dos funcionários e validadas com o sindicato. Antes disso, era pago o valor da participação nos lucros, definido pelo acordo com o sindicato, que era independente do alcance das metas estipuladas.

As metas relacionadas à remuneração variável para os funcionários da produção são avaliadas mensalmente no nível da fábrica. O potencial de remuneração variável é de até três salários por ano. São considerados no modelo de remuneração indicadores como absenteísmo, horas produzidas, produtividade e total de despesas operacionais. Cada indicador é vinculado a uma premiação específica, o que permite que o funcionário saiba quanto irá receber por meta atingida. Os valores apurados de cada meta são divulgados em um quadro na fábrica.

É interessante notar o posicionamento do sindicato da categoria acerca deste modelo. Segundo um representante deste sindicato, a diferenciação da remuneração variável entre funcionários, a partir da distinção de suas contribuições individuais, é altamente desaconselhável. $\mathrm{O}$ argumento utilizado remete à "igualdade de importância" entre todos os funcionários, independentemente de seu desempenho. A diferenciação de reconhecimento, de acordo com a performance, incentivaria a "competitividade predatória", que teria efeitos maléficos. Assim sendo, este sindicato só endossou o modelo remuneração variável adotado pela empresa 1 por ele não prever diferenciação de reconhecimento entre os funcionários.

Na empresa 2, no âmbito da produção, o PPR vinculado ao cumprimento de metas foi implementado já em 1998, após negociações com o sindicato. Antes disso, era praticada a remuneração variável atrelada à negociação sindical, menos objetiva e que não estava atrelada ao desempenho dos grupos ou dos indivíduos. No início de todos os anos são negociadas com o sindicato dos químicos as metas a serem perseguidas no período, após terem sido aprovadas internamente pela comissão de remuneração variável. 
Para o nível operacional, $20 \%$ do potencial de remuneração variável é determinado a partir do resultado operacional da empresa (mesmo havendo algumas reclamações de funcionários, que dizem que pouca influência tem sobre esta variável) e os outros $80 \%$ são provenientes dos indicadores da fábrica relacionados à segurança, qualidade e produtividade. Cada meta é mensurada individualmente, deixando clara a contribuição de cada uma delas para o resultado final. O potencial de remuneração variável é de um salário ao ano, podendo chegar, em caso de extrapolação das metas, a 1,2 salários. A apuração destes indicadores é mensal, divulgada por meio de quadro de avisos. A mínima unidade de avaliação é o grupo, apesar de que, o que conta, para a remuneração variável, são os indicadores consolidados da fábrica.

A empresa 3 também adota um esquema de remuneração variável na produção, composto da seguinte forma: $70 \%$ advém de indicadores financeiros da operação no Brasil, mensurados por meio de faturamento e lucro. Outros $15 \%$ são provenientes de metas relacionadas ao nível de serviço prestado aos vendedores da empresa. Os 15\% restantes são provenientes de metas da área de manufatura, em que são mensurados acidentes, economias na produção, índice de rejeição por má qualidade e eficiência da linha. O potencial de ganho adicional é de 1 a 2 salários por ano. $\mathrm{O}$ acompanhamento das metas é mensal.

Além disso, todos os funcionários, inclusive os da produção, têm um plano de desenvolvimento de performance (PDP), em que basicamente são avaliadas metas individuais ou em grupo, e competências. O resultado da avaliação deste plano pode aumentar ou reduzir os valores provenientes do PPR. Na produção, as metas do PDP são algumas das metas do grupo semi-autônomo. Assim, na prática, um grupo de melhor desempenho pode ter um valor de remuneração variável maior que os componentes de um grupo de pior desempenho. Além disso, na parte do plano referente à avaliação de competências, a avaliação é individual e realizada entre os membros do grupo. Desta forma, a empresa prevê em suas práticas de gestão de pessoas que um funcionário de um grupo tenha remuneração variável diferente de outro funcionário do mesmo grupo, em função dos resultados de suas avaliações de competências.

Já na empresa 4, a cultura de indicadores sempre foi muito forte. Alguns dos indicadores da manufatura são utilizados no PPR, que é estendido a todos os operadores. Para este público, $30 \%$ das metas se referem a objetivos regionais de economia na produção. Outros $30 \%$ do programa se relacionam a metas de eficiência operacional da fábrica. Os $40 \%$ restantes do programa correspondem a 3 ou 4 metas estipuladas pelos gerentes de produção com as comissões de funcionários que são apuradas no nível das células. Cada gerente tem autonomia para nego- ciar com suas células quais indicadores serão utilizados no programa.

No que se refere à remuneração variável, a unidade mínima de análise é a célula, uma vez que os indicadores destas unidades são considerados, com peso relevante, na constituição do valor a ser distribuído. A empresa não cogita adotar uma análise individualizada de desempenho na produção. A intenção é estimular sempre o trabalho em grupo na produção.

\subsection{A difusão da lógica da geração de valor ao acionista na produção}

Na empresa 1, o foco de trabalho com os funcionários não tem sido explicitamente a maximização do valor da ação para o acionista. Porém, o aumento da produtividade e do comprometimento tem sido trabalhado pela gestão da empresa. Além da adoção de grupos autogeridos, das práticas de remuneração variável e de avaliações de desempenho, a empresa vem realizando ações que visam promover maior sentido de pertencimento à empresa $\mathrm{e}$ comprometimento com seus objetivos.

Na empresa 2, a gestão procura deixar claro aos operadores que $80 \%$ do potencial de sua remuneração variável está totalmente sob responsabilidade dos próprios operadores e que caso se esforcem para produzir melhores resultados, serão beneficiados. No entanto, os gestores entrevistados deixam claro que boa parte dos funcionários ainda não sabe trabalhar com este modelo. Muitos deles ainda não se sentem responsáveis por este resultado, julgando sua remuneração decorrente de um "extra". Fica claro, portanto, que o comprometimento com as metas, a partir do oferecimento de remuneração variável, ainda não está muito presente na empresa.

Um problema deste tipo de incentivo exposto pelos gestores entrevistados foi o pagamento anual. Os funcionários, por não identificarem que haverá um pagamento no curto prazo, acabam se comprometendo menos com o alcance das metas.

Com relação à autonomia, os entrevistados deixam claro que os funcionários têm a percepção de que podem influenciar o resultado da empresa, mas ainda não têm claro de que forma podem contribuir. A gestão da empresa tem se esforçado para disseminar a cultura de acompanhamento de indicadores, mas não se percebe que os funcionários estejam motivados a perseguir com obstinação maiores patamares de desempenho.

Segundo os gestores entrevistados na empresa 3, a busca por superação de metas na produção já faz parte da cultura da empresa. As pessoas são inseridas neste contexto desde o momento da integração, logo após sua admissão. Produtos da empresa ou brindes são oferecidos como forma de reconhecimento.

Apesar de o PPR existir há mais de 5 anos na empresa 4, tem-se a impressão de que o engajamento dos funcioná- 
rios com os resultados da célula, da fábrica e da empresa ainda não é o desejado. Segundo o gestor entrevistado, apesar de haver comunicação e muitos acompanharem o andamento do programa, há funcionários que só se lembram do PPR no momento do pagamento, não dando atenção às metas ao longo do ano. Novamente surge a idéia, entre os funcionários, de que a remuneração variável obtida atrelada ao alcance de metas é apenas "algo a mais", não incentivando a busca constante por melhores resultados. O entrevistado deixou muito claro que há necessidade de se apurar e divulgar sistematicamente as metas (caso contrário, elas são esquecidas). A fim de aumentar a efetividade neste acompanhamento, estão sendo realizadas reuniões mensais referentes ao assunto com os representantes de linhas.

\section{Análise comparativa dos casos}

A partir da apresentação dos casos, torna-se possível realizar algumas análises importantes para se chegar às conclusões do presente trabalho. Até que ponto a mentalidade de geração de valor ao acionista chega aos funcionários da produção das empresas pesquisadas? $\mathrm{O}$ que atua a favor e o que tem dificultado a difusão desta mentalidade nas empresas? A adoção de desenhos flexíveis de organização do trabalho na produção de fato auxiliou a fazer com que os funcionários se tornassem mais responsáveis e, consequentemente, fará com que ajam mais pró-ativamente para a consecução dos objetivos organizacionais relacionados à criação de valor? Estas são questões centrais relacionadas à hipótese básica deste trabalho e que serão exploradas a seguir.

Inicialmente, percebe-se que, apesar de haver evidências significativas da importância da questão da geração de valor para o acionista nas quatro empresas estudadas, mesmo que em diferentes graus, em nenhuma delas foi possível observar este tema sendo formalmente abordado na produção, apesar dos gestores de produção serem claramente cobrados por objetivos financeiros. Aparentemente estes gestores não repassam estes objetivos de forma clara à produção. Parece não ficar clara, para os funcionários da produção, a relação entre seus esforços, bem como o alcance de metas operacionais e a obtenção dos objetivos organizacionais de rentabilidade.

No entanto, é notório o movimento que está sendo realizado no sentido da adoção das ferramentas de gestão de pessoas apresentadas neste trabalho como vetores da difusão da mentalidade de geração de valor. As quatro empresas pesquisadas implementaram instrumentos de avaliação e de remuneração por objetivos, pautados em indicadores - na grande maioria das vezes - quantitativos, conforme sugerem os autores citados na seção 3.1.2, o que segundo eles é um passo relevante para incentivar os funcionários a buscarem maior desempenho e melhoria de indicadores operacionais.

Porém, apesar deste movimento, há pontos da implementação destes instrumentos que divergem do que é proposto pela literatura. A primeira (e talvez principal) divergência na implementação das ferramentas de gestão de pessoas é que praticamente nenhuma empresa pesquisada reconhece as pessoas individualmente. Conforme exposto na Tabela 1 apenas a empresa 3 busca diferenciar o desempenho e reconhecê-lo em nível individual, e ainda assim de forma indireta (por meio da avaliação de competências previstas no plano de desenvolvimento de performance, que influencia os valores a serem distribuídos pelo PPR). Além disso, é curioso que mesmo todas as empresas pesquisadas tendo adotado grupos de trabalho, ainda assim, somente as empresas 3 e 4 adotam indicadores do grupo para o reconhecimento - as empresas 1 e 2 adotam como mínima unidade de análise a fábrica. (Tabela 1)

Apesar da dificuldade de se chegar à avaliação individual, é importante ressaltar ainda a iniciativa de duas empresas (1 e 2) de buscar avaliações de desempenho individual. Embora estas avaliações se pautem mais em questões qualitativas, as empresas vêem esta questão como um incentivo à capacitação para futuras melhorias de desempenho.

Outra divergência em relação à literatura estudada está no fato de se explorar muito pouco indicadores financeiros no nível da produção. Além disso, quando são utilizados, referem-se à empresa inteira e não ao resultado da fábrica ou da célula (Tabela 2). Mesmo que não sejam utilizados indicadores financeiros para a produção por conta da dificuldade de sua apuração, a literatura recomenda explorar a ligação dos indicadores operacionais e os resultados financeiros. Aparentemente não foram criados meios ou canais de comunicação sobre este assunto, com exceção da empresa 3, que expõe indicadores financeiros influenciados pelos grupos semi-autônomos a seus funcionários, apesar de não utilizá-los como base do modelo de remuneração variável.

Tabela 1. Nível de diferenciação do reconhecimento financeiro, baseado em desempenho, entre os funcionários da produção. (MARX; SOARES, 2008).

\begin{tabular}{lcccc}
\hline \multicolumn{1}{c}{ Diferenciação do reconhecimento } & Empresa 1 & Empresa 2 & Empresa 3 & Empresa 4 \\
\hline Fábrica & $x$ & $x$ & & $x$ \\
Grupo/célula & & & $x$ & \\
Funcionário & & & $x$ \\
\hline
\end{tabular}


Tabela 2. Composição (por tipo de indicador) dos modelos de remuneração variável dos funcionários da produção das empresas pesquisadas. (MARX; SOARES, 2008).

\begin{tabular}{llcccc}
\hline Tipo de indicador & \multicolumn{1}{c}{ Nível } & Empresa 1 & Empresa 2 & Empresa 3 & Empresa 4 \\
\hline Operacional & Empresa/divisão & & & $15 \%$ & $30 \%$ \\
& Fábrica & $100 \%$ & $80 \%$ & $15 \%$ & $30 \%$ \\
& Grupo/célula & & & & $40 \%$ \\
& Funcionário & & & & \\
\hline Financeiro & Empresa/divisão & & $20 \%$ & & \\
& Fábrica & & & \\
& Grupo/célula & & & \\
& Funcionário & & & & \\
&
\end{tabular}

Ainda com relação à implementação das ferramentas de gestão de pessoas, vale citar um outro problema, levantado nas empresas 2 e 4: o pagamento anual. Assim como o problema da apuração dos indicadores somente no nível muito macro, o reconhecimento num período muito distante daquele que está ocorrendo a ação também faz com que o operador não perceba a vinculação do seu trabalho ao reconhecimento que eventualmente ele irá receber no futuro, caso as metas sejam alcançadas.

Outro questionamento fundamental é acerca da adoção dos grupos semi-autônomos. Eles parecem ajudar, na prática, ao que se refere à discussão, adoção e avaliação de indicadores. No entanto, o principal ponto que relaciona os novos modelos flexíveis de trabalho na produção à criação de valor, que é a autonomia no trabalho, ainda parece pouco maduro na prática. Aparentemente este é o ponto de mais difícil adoção na implementação dos grupos. Nas empresas 1 e 2 foi explicitado pelos gestores, que os funcionários ainda têm dificuldade de se sentirem "donos" dos processos. Na empresa 4, o papel do supervisor ainda não pôde ser suprimido.

\section{Conclusões}

O presente trabalho procura elucidar as influências da mentalidade da geração de valor ao acionista nas práticas de gestão de pessoas no âmbito da produção. A partir de uma revisão pertinente da literatura sobre o tema e de uma pesquisa de campo, algumas conclusões puderam ser geradas.

Como primeira conclusão, pode-se afirmar que apesar de haver um movimento claro das empresas pesquisadas rumo à utilização de ferramentas de gestão de pessoas que auxiliem na difusão da mentalidade de criação de valor ao acionista, esta mentalidade ainda não chegou de forma consistente na produção. Conforme apresentado na análise dos casos, é exercida uma pressão por maiores resultados financeiros sobre os gestores da produção. No entanto, esta pressão não pôde ser observada de forma mais clara no restante da produção. É fato que, em todas as empresas pesquisadas tenha havido a implementação de modelos de gestão de pessoas que, em tese, estimulam a maior produtividade e que reconhecem financeiramente o funcionário, caso os objetivos traçados sejam alcançados. Porém, a cobrança exercida sobre eles ainda se traduz essencialmente em termos operacionais. Para a produção, parece não ter havido mudanças significativas de mentalidade em relação à época da lógica produtivista, conforme Froud et al. (2000). Percebe-se que não só a pressão, mas também a conscientização acerca dos resultados financeiros da empresa é restrita aos gestores da produção.

Algumas razões podem ser apontadas como possíveis causas desta constatação. A primeira delas está relacionada à própria natureza das empresas escolhidas para se realizar a pesquisa. No presente trabalho, foram abordadas empresas manufatureiras tradicionais, que adotam em suas operações brasileiras desenhos flexíveis de organização do trabalho na produção. O intuito desta escolha foi o de buscar observar na prática a relação entre os desenhos organizacionais que conferem ao funcionário da produção maior autonomia e a difusão da lógica da geração de valor ao acionista, conforme exploram Zilbovicius e Dias (2005). No entanto, é possível que esta relação ainda seja prematura, dado que a própria mentalidade de geração de valor para o acionista nas empresas analisadas ainda parece não ser suficientemente intensa para gerar tamanha alteração de comportamento nos funcionários da produção. Desta maneira, torna-se uma rica oportunidade de estudos futuros pesquisar empresas que não necessariamente adotam desenhos organizacionais mais flexíveis na produção, mas que estejam mais intensamente inseridas no contexto de geração de valor para o acionista, tais como empresas com capital proveniente de venture capital ou private equity, conforme explorado no início deste trabalho.

Outra possível causa do não comprometimento dos funcionários da produção com a geração de valor ao acionista é o fato dos gestores da produção não terem levado adiante para seus subordinados a questão do retorno finan- 
ceiro. No âmbito dos grupos semi-autônomos, Salerno (1998) ressalta a necessidade de se trabalhar a dimensão normativa da comunicação, em que se estabelece o alinhamento dos funcionários quanto à compreensão sobre o que é mais relevante do ponto de vista da eficiência e dos objetivos da produção. No entanto, estes pontos não puderam ser observados nas empresas pesquisadas. Uma primeira hipótese acerca deste fato é a de que os gestores tenham negligenciado a parte social deste tipo de mudança. Como nenhuma das empresas pesquisadas nasceu na época da lógica financeira, conforme explora Froud et al. (2000), elas tiveram que se adequar a esta nova ordem, o que se daria por meio de grandes processos de mudança organizacional. Segundo Selfridge e Sokolik (1975), um processo de mudança como o que está sendo estudado, para que seja efetivo, deve contemplar, além de aspectos técnicos, aspectos comportamentais. As áreas de $\mathrm{RH}$, que em tese poderiam auxiliar na condução da dimensão social do processo de mudança, ainda desempenham timidamente este papel. Parece que, para os gestores da produção, os profissionais de RH possuem pequeno poder de contribuição. Talvez por isso não pôde ser percebida coerência entre os diversos processos de recursos humanos com a mentalidade de geração de valor, conforme trabalhado na seção 3.2.

Outra hipótese que pode explicar o fato dos gestores não terem explorado a lógica da geração de valor junto aos funcionários da produção é mais simplista, porém nem por isso menos relevante e provável: é possível que os gestores acreditem que os funcionários da produção não tenham capacidade de entendê-la. Apesar de não terem sido coletadas evidências nas entrevistas neste sentido, este ponto é tratado na própria literatura estudada.

Ainda no que se refere à dificuldade de se levar a lógica de geração de valor à produção, deve-se lembrar de um problema conceitual na implementação dos modelos de gestão de pessoas que em tese contribuiriam para a difusão desta lógica. Ao contrário do que é sugerido pela literatura, os indicadores utilizados são mensurados na maioria das vezes no âmbito da fábrica ou da empresa, dificultando a percepção por parte do funcionário da produção acerca da sua contribuição individual para os resultados alcançados. Além da resistência de sindicatos à individualização do reconhecimento atrelado ao desempenho, observou-se em parte das entrevistas com os gestores um discurso de que "deve-se privilegiar o trabalho em grupo, reconhecendo os resultados alcançados pela equipe", idéia esta coerente com a proposta da escola sociotécnica de organização do trabalho.

É interessante notar que, a ausência da difusão da mentalidade de geração de valor ao acionista na produção corrobora com a pesquisa realizada por Ramires (2005). Apesar de adotar um enfoque diferente em sua pesquisa, relacionado à influência da financeirização sobre o modo de organização e de gestão da área de manufatura, Ramires (2005, p. 81) chega a conclusões bastante semelhantes às do presente trabalho. $\mathrm{O}$ estudo de Ramires (2005) também aponta mudanças no sistema técnico de gestão na produção por conta da lógica de geração de valor, mas pouco foco na mudança de comportamento dos funcionários da produção. $\mathrm{Na}$ empresa estudada por este outro autor, somente os gestores receberam treinamento e, assim como nas empresas estudadas no presente trabalho, a "alfabetização em finanças" não ocorreu para os funcionários da fábrica.

Vale ressaltar, ainda, que evidências coletadas na pesquisa de campo contrapõem o pressuposto de toda a literatura da geração de valor para o acionista: o de que todos os funcionários de uma empresa se mobilizariam em torno da "causa" de geração de valor se percebessem que também são reconhecidos financeiramente por sua contribuição à geração de valor. $\mathrm{O}$ fato de se poder buscar um "algo a mais", por conta do alcance de metas, pode não ter mobilizado os funcionários destas empresas. Assim sendo, um pressuposto fundamental da lógica da geração de valor, que já é muito contestada por autores como Casado (2002) e Wood Jr. e Picarelli Filho (1999), foi questionada também na prática.

Concluindo, percebe-se que a hipótese básica deste trabalho não pôde ser completamente comprovada. Apesar de serem percebidas mudanças nas práticas de gestão de pessoas na produção das empresas escolhidas, de forma a apresentar modelos de remuneração variável aplicados a todos os funcionários da produção, a apuração de resultados e o reconhecimento não são realizados de forma individualizada. Por este e pelos outros motivos mencionados nesta seção, não pôde ser constatada a difusão da lógica de geração de valor ao acionista no ambiente da produção. 


\title{
Influence of shareholder value on people management practices in the production environment
}

\begin{abstract}
This paper aims to add to the body of knowledge about the influence of the shareholder value on people management practices, with emphasis on the production environment. The paper begins with an overview of the origins and fundaments of finance and value generation concepts for company shareholders, with the main focus on the increase of share prices. An analysis is then made of the interface between these concepts and people management practices, exploring the bidirectional nature of this interface, since the human resources function is not only influenced by company guidelines but is also considered one of the main forms for helping disseminate it, in view of its role as an agent of change in company behavior. As such, the three main elements are examined, which, according to the literature, comprise this interface: variable compensation, performance management and work autonomy. Lastly, a multiple case study is presented to verify how the financial concept of companies has been influencing these people management practices at the production level of companies operating in Brazil, and to what extent these practices have contributed to disseminate the shareholder value mentality. The findings of this study indicate that, at the conceptual level, the influence of shareholder value on people management practices is indisputable, but that in practice its effect is still only minor, although changes in this direction are already occurring.
\end{abstract}

Keywords: Shareholder value. Managing for value. Human resource management. Work performance. Autonomy at work. Variable income.

\section{Referências bibliográficas}

BECKER, B.; HUSELID, M.; ULRICH, D. Gestão estratégica de pessoas com Scorecard - interligando pessoas, estratégia e performance. Rio de Janeiro: Campus, 2001. p. 260.

CASADO, T. A motivação e o trabalho. In: FLEURY, M.T. et al. As pessoas na organização. São Paulo: Gente, 2002. p. 306

CHIAVENATO, I. Gestão de pessoas. Rio de Janeiro: Campus, 2004. p.529.

DIMAGGIO, P. The twenty-first-century firm: changing economic organization in international perspective. Princeton: Princeton University, 2001. p. 275.

DUTRA, J.S. Competências: conceitos e instrumentos para a gestão de pessoas na empresa moderna. São Paulo: Atlas, 2004. p. 206.

EHRBAR, A. EVA: the real key to creating wealth. New York: Jonh Wiley \& Sons, 1998. p. 256.

EISENHARDT, K. M. Building theories from case study research. Academy of Management Review, Briar Cliff Manor, v. 14, n. 4, p. 532-550, 1989.

FAMA, E. F. Agency problems and the theory of firm. Journal of Political Economy, Chicago, v. 88, n. 2, p. 288-307, 1980.

FLIGSTEIN, N. The architecture of markets: an economic sociology of twentyfirst-century capitalist societies. Princeton: Princeton University, 2002. p. 288.

FROUD, J.; HASLAM, C.; JOHAL, S.; WILLIAMS, K. Shareholder value and financialization: consultancy promises, management moves. Economy and Society, Oxfordshire, v. 29 , n. 1 , p. 80-110, 2000.

Hamel, G. O futuro da administração. São Paulo: Campus, 2007. p.272.

HARGADON, A.; FANELLI, A. Action and possibility: reconciling dual perspectives of knowledge in organizations. Organization Science, Hanover, v. 13, n. 2, p. 290-302, 2002.
HANSEN, M; NOHRIA, N.; TIERNEY, T. What's your strategy for managing knowledge? Harvard Business Review, Boston, v.77, n.2, p.106 - 116, mar./apr. 1999.

HIPOLITO, J. A. M.; REIS, G. G. A avaliação como instrumento de gestão. In: FLEURY, M.T. et al. As pessoas na organização. São Paulo: Gente, 2002. p. 306

HIPOLITO, J. A. M. Sistemas de recompensas: uma abordagem atual. In: FLEURY, M.T. et al. As pessoas na organização. São Paulo: Gente, 2002. p. 306

MARRAS, J. P. Administração da remuneração. São Paulo: Pioneira Thomson Learning, 2002. p.312.

MARX, R. Trabalho em grupos e autonomia como instrumentos da competição. São Paulo: Atlas, 1997. p.165.

PRAHALAD, C. K.; HAMEL, G. The core competence of the corporation. Harvard Business Review, Boston, v. 68, n. 3, p. 79-91, 1990.

RAMIRES, R. B. Valor econômico agregado em organizações: um estudo de caso. São Paulo, 2005. p.90. Dissertação (Mestrado em Engenharia de Produção), Escola Politécnica da Universidade de São Paulo - USP.

SALERNO, M. S. Projeto organizacional de produção integrada, flexível e de gestão democrática: processos, grupos e espaços de comunicação-negociação. São Paulo, 1998. p.259. Tese (livre-docência em Engenharia de Produção), Escola Politécnica da Universidade de São Paulo - USP.

SELFRIDGE, R.; SOKOLIK, S. A comprehensive view of organizational development. MSU Business Topics, East Lansing, v.5, n.10, p. 46-61, winter 1975.

SOARES, J.P.R.F A Influência da orientação às geração de valor ao acionista nas práticas de gestão de pessoas. São Paulo, 2006. p.133. Dissertação -(Mestrado em Engenharia de Produção), Departamento de Engenharia de Produção, Universidade de São Paulo - EPUSP. 
STERN, J. M.; SHIELY, J. S.; ROSS, I. The EVA challenge: implementing value added change in an organization. New York: Jonh Wiley \& Sons, 2001. p.256.

STEWART, G. B. The Quest for value. New York: HarperCollins, 1991. p.781.

USEEM, M. Investor capitalism: how money managers are changing the face of corporate America. Directorship, Boston, v. 22, n. 5, p. 3-5, 1996.
WOOD JUNIOR, T.; PICARELLI FILHO, V. Remuneração estratégica: a nova vantagem competitiva. 2. ed. São Paulo: Atlas, 1999. p.224.

ZILBOVICIUS, M.; DIAS, A. V. C. Working for value creation: some issues on financialisation and new forms of work organization. In: Anais do TREZIEME RENCONTRE INTERNATIONALE DU GERPISA, 2005, Paris.

\section{Sobre os autores}

\section{Roberto Marx}

Departamento de Engenharia de Produção, Escola Politécnica - USP, Av. Prof. Almeida Prado, 128, CEP 05508-900, São Paulo, SP, Brasil, e-mail: robemarx@usp.br

\section{João Paulo Reis Faleiros Soares}

Departamento de Engenharia de Produção, Escola Politécnica - USP, Av. Prof. Almeida Prado, 128, CEP 05508-900, São Paulo, SP, Brasil, e-mail: jpfaleiros@uol.com.br 